\title{
Virtual Environment of Learning to Support the Topic of Proportionality at Elementary Levels
}

\author{
Elena Fabiola Ruiz Ledesma ${ }^{1}$, Lorena Chavarría Báez ${ }^{1}$, Laura Ivonne Garay ${ }^{2}$ \\ ${ }^{1}$ Instituto Politécnico Nacional, Departamento de Posgrado SEPI-ESCOM, \\ Mexico City, Mexico \\ ${ }^{2}$ Instituto Politécnico Nacional, UPIITA, \\ Mexico City, Mexico \\ efruiz@ipn.mx, lchavarria@ipn.mx, lgaray@ipn.mx
}

\begin{abstract}
This article describes the technological and educational factors involved in the development of the educational software proposal named Dwarfs and Giants, which is expressed as a Virtual Environment of Learning developed under the standard Sharable Content Object Reference Model in its version 1.2. This tool lends a helping hand to the teacher in the classroom. It has activities, according to the studying plan of the Secretaría de Educación Pública in Mexico. To strengthen the topics of ratio and proportion in students of the sixth grade of elementary school. The VLE was tested and used by a group of 28 students in the sixth grade of elementary school during 8 sessions, once every week. As field research these students answered some initial questions before using the software and answered some more questions at the end. Meaningful attainments were obtained and these are shown in the information given by the teacher in charge of the group and related to the raising of the grade in the mathematics exams from various students. There was an increase in the final evaluation compared to the initial one ( $43.2 \%$ to $73.2 \%)$. When applying the test t-student, a statistically meaningful difference was observed $(\mathrm{p}<0.005)$, that is why the VLE is considered to have had profound positive impact on the students' learning.
\end{abstract}

Keywords: Virtual learning environments, agile methodologies to develop software, object-oriented programming, SCORM.

\section{Introduction}

The use of the Information and Communication Technologies (ICT) in the teachinglearning process has been increased in recent years and it has had a powerful impact due to the fact that more people can access knowledge without being present in a classroom, as well as the outstanding decrease of time to make educational material to convey topics. In this regard, Mendoza [1] comments that the challenge of bringing ICT into the classroom is not only what can be related to the infrastructure or the acquisition of technological resources, but also the way how the teacher works with them, when you use them, for what and what hopes to achieve learning in students. 
The elementary education is the basement of people's professional development. According to the results of the Census of Population and Housing conducted by the National Statistics Institute and Geography [2], Mexico has a population of $119,530,753$ people, of which 35.2 million are enrolled as students in basic school education, accounting 73.4\% of enrollment in the education system [3]. On the other hand, according to the Organization for Economic Cooperation and Development Economic (OECD) about 55\% of students did not achieve the level of basic skills in math test [4]. [5]. Although this problem is multifactorial, one of the causes is due to the poor development of the concepts and skills that children have in the elementary school, one of the concept is ratio and proportion, because that permit to the student development his/her the proportional thinking, which is a cognitive characteristic of people [6]. A human being has the proportional thinking totally developed when he/she can explain this relation of relations not only qualitatively, by using intuition, but also quantitatively. So, there are two aspects of the proportional thinking: the qualitative proportional thinking and the quantitative proportional one.

There are educational models that support the development of the qualitative and quantitative proportional thinking in children according to what is shown by Piaget in [7]. Such educational models were developed by Ruiz [6]. For so doing, Ruiz used drawings, physical objects, classical literature tales, puppets and some other educational materials. This article shows part of the investigation, and emphasizes the use of technology to implement as a Virtual Learning Environment (VLE) the work done by Ruiz. Some of the models created by Ruiz are known as "The development of a party room", and "The house furniture". In the last one the student uses graphic elements to hold relations among the furniture of a house by using verbal categories (bigger than, smaller than, etc.). Through the use of the proposed VLE the proportional thinking of the students was benefited.

The rest of the paper is organized as follows: section 2 describes the role of the technology in education. Section 3 depicts the VLE developed. Section 4 shows the implementation. Section 5 describes the preliminary results. Section 6 presents the conclusion. Finally, the references are depicted.

\section{Technology in Education}

Nowadays, the use of technology is everywhere in our lives and education is not an exception. Education is benefited from educational software and from the Internet, among others, the first one employs, computationally speaking, pedagogical activities that support the understanding of concepts [8], the second one, Internet; lets the knowledge be gotten by more people without needing to be present in a classroom. When combining these technologies a more robust software which is known as Virtual Environment of Learning (VLE). A VLE is a computational system designed to facilitate the management of resources of learning [9].

Something important when developing VLEs is the use of standards to guarantee quality tools that fulfill the desired needs and goals. The Sharable Content Object Reference Model (SCORM) was created to establish principles and guides to work which are needed to develop and implement efficiently, effectively and on a broad scale, education about new web technologies [10]. Such standard is adapted to the 
definition of Learning Object (LO), a digital or not digital entity which can be used in learning, education or training [9]. The LO is more philosophy than technology itself which is based on the stream of the sciences of computing known as object-oriented programming. By now the LO's lack of a universally accepted definition and they are polemical too [11], [12].

SCORM divides the world of technology in functional components which are:

- Sharable Content Object (SCO): content that can be supported by a Web browser and it can send information to the system. It is divided into: simple SCO and data management SCO. The minimum unit of the SCOs is the Assets.

- $\quad$ Learning Management System (LMS) is software for Internet-Intranet servers and also manages the learning resources. It manages users, learning resources and communication services, and sends learning resource videos to the student.

- The bidirectional communication through an API among the SCOs and the LMS which uses 15 defined variables by the standard used to exchange data.

Mixing technology and education is a good choice to modernize the teaching learning process; however, developing the right tools is something really challenging in different ways. First, it must be considered what to teach and how to do it, it means: 1) identifying the course or topic to be taught as there are lots of topics, and the ones to be chosen are the ones to which we need to pay more attention, and it depends on their difficulty or on their importance related to the following subjects, and 2) developing activities that support the topic to be taught, and their benefits. Second, the available technological tools must be analyzed so as to implement the activities of the first step to set up functional systems. And, finally, it is compulsory to evaluate the use of colors, shapes, visual designs, uses, contents, skills, etc. of the concerning group of study. In this sense, the Latin American Institute for Educational Communication (ILCE), in coordination with the Secretaría de Educación Pública (SEP) [13]. In Mexico, in 1997 created a school network taking into account students, teachers, parents and principals of public primary schools. Such network is aimed at bringing to the schools, through the use of Internet, educational opportunities and materials of great relevance based on the existing SEP's study plans and programs to help to improve the quality of teaching. Educational authorities began to direct their efforts towards the establishment of Information and Communication Technologies (ICT) in basic education. In 2003 "Enciclomedia" made its appearance in the educational scenario. The main idea which gives rise to it is the digitalization of free textbooks, supplemented with audiovisual and interactive resources. The primary objective of this educational supplement is that students in public elementary schools in Mexico, with a more significant learning, encouraging interaction, teamwork in the classroom and cooperation of society to improve overall quality education. But these objectives were not achieved for various reasons, focusing on public policy [14], [15]. Nowadays, members of the Educational Computer Network as part of Network Computing IPN develop projects aimed at incorporate technology into education through the construction of a laboratory for the development of computer-educational resources for different educational levels [16]. One of these resources is shown in this article, and has been developed for primary education on the topic of ratio and proportion this is related to the proportional thinking which lets someone, after a certain mental process; establish the relation of equivalence between quotients of lengths [6]. 


\section{Dwarfs and Giants}

Dwarfs and Giants is educational software, created as a VLE, which is an aiding tool to the teacher in the classroom to teach the topic of the proportional thinking. It has the crucial features of an VLE which are: management of information, definition of the user roles (manager, professor, and student), authentication of the users in the system, implementation of activities structured as courses, standardization of the tools for activities containing SCORM, text and image questioning that can be auto evaluated as well as certain personalizing of the graphic interface.

\subsection{Types of Users}

Table I shows specific actions each kind of user can do according to their role.

Table 1. Users' functionality.

\begin{tabular}{ccl}
\hline \multicolumn{1}{c}{ Role } & \multicolumn{1}{c}{ Funcionality } \\
\hline Administrator & - & $\begin{array}{l}\text { Administration of students, professors, } \\
\text { groups. }\end{array}$ \\
& - & $\begin{array}{l}\text { Changing of the user's password. } \\
\text { Restoration of the professors \& students' } \\
\text { password. } \\
\text { Enrollment and change of group of students }\end{array}$ \\
\hline Profesor & - & $\begin{array}{l}\text { Administration of question papers, learning } \\
\text { resources. } \\
\end{array}$ \\
& - & $\begin{array}{l}\text { Monitoring the student's academic record. } \\
\text { Group statistics, reporting the academic } \\
\text { information generated of the group students. } \\
\text { Internet forum, chatting, changing of } \\
\text { password. }\end{array}$ \\
\hline Student & - & $\begin{array}{l}\text { Use of the learning resources (activities \& } \\
\text { courses), forum y chat. }\end{array}$ \\
\hline
\end{tabular}

\subsection{Architecture}

Dwarfs and Giants takes the architecture IEEE 1484 Learning Technology Systems Architecture (LTSA) [24], established by the Institute of Electrical and Electronics Engineers Learning Technology Standards Committee (IEEE LTSC), as a reference to identify the components. The IEEE 1484 LTSA architecture adapts to each critical part of a VLE: students, repository of the learning resources, tutors (professors), storage the student's personal information and academic record, as well as iteration among its components. The IEEE 1484 LTSA architecture adapts perfectly to the Client - Server model [17]. One of the advantages of this architecture is portability as the resources are stored in the server and the client just needs to access to Internet from an intranet or on the Web.

Dwarfs and Giants uses the version 1.2 of SCORM. In fact, SCORM does not validate the contents of the learning resources that integrate the SCOs, as it just maps the learning integrating resources according to the rules established to be transparent in 
the systems using the standard. Besides the components used by the architecture IEEE 1484, Dwarfs and Giants uses tools that promote the collaborative learning as those ones of a forum of discussion or a chat. Figure 1 shows the general architecture of Dwarfs and Giants based on the IEEE 1484 LTSA architecture and the Client - Server model.

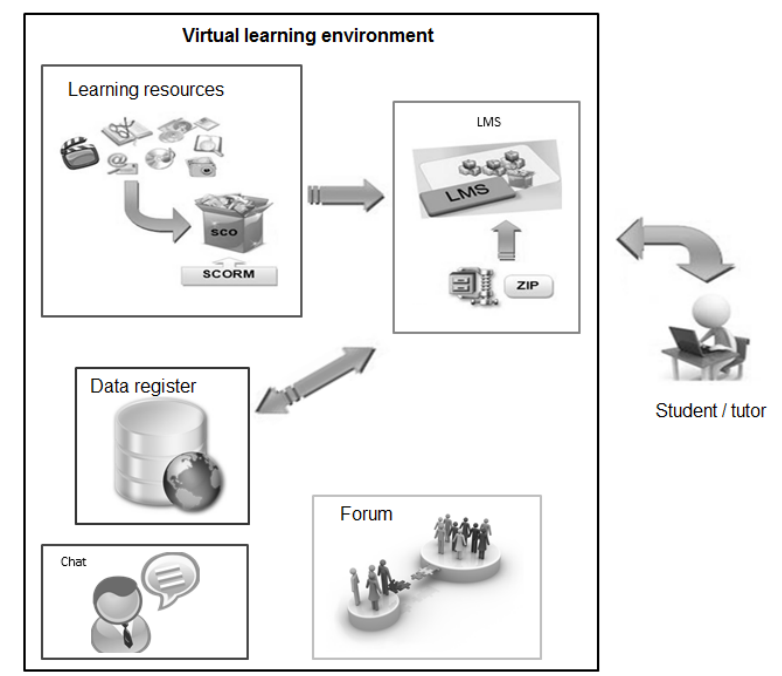

Fig. 1. General architecture of Dwarfs and Giants.

\subsection{Technologies Used}

It was decided to use 1) MySQL as Database, 2) PHP as the programming language, of the server to obtain information of the database and to launch the content of learning resources, 3) HTML in combination of JavaScript and CSS to show the multimedia content on the side of the client, and 4) AJAX to send and receive data asynchronously to update specific components on the page, taking into account the standards of the World Wide Web Consortium (W3C) [18], [19], to execute on the commonly used browsers: Internet Explorer 8, Google Chrome, Mozilla Firefox, Safari and Opera.

\section{$4 \quad$ Implementation}

Using the learning model by Ruiz [6], activities were selected to help the student to acquire the concept of proportional thinking in its two parts. Dwarfs and Giants takes the structure of an LO based on a course: diagnostic questionnaire, introduction to the topic, activities for the qualitative a quantitative proportional thinking and the final evaluation. The initial screen of Dwarfs and Giants (see Figure 2) has a menu having the initial options: start session, colors and contacts. In the menu colors a list of colors is displayed on the left so as to personalize the interface. Each user must enter the user's name and the password in order to access the system, depending on their privileges, as mentioned, feasible actions are shown. 


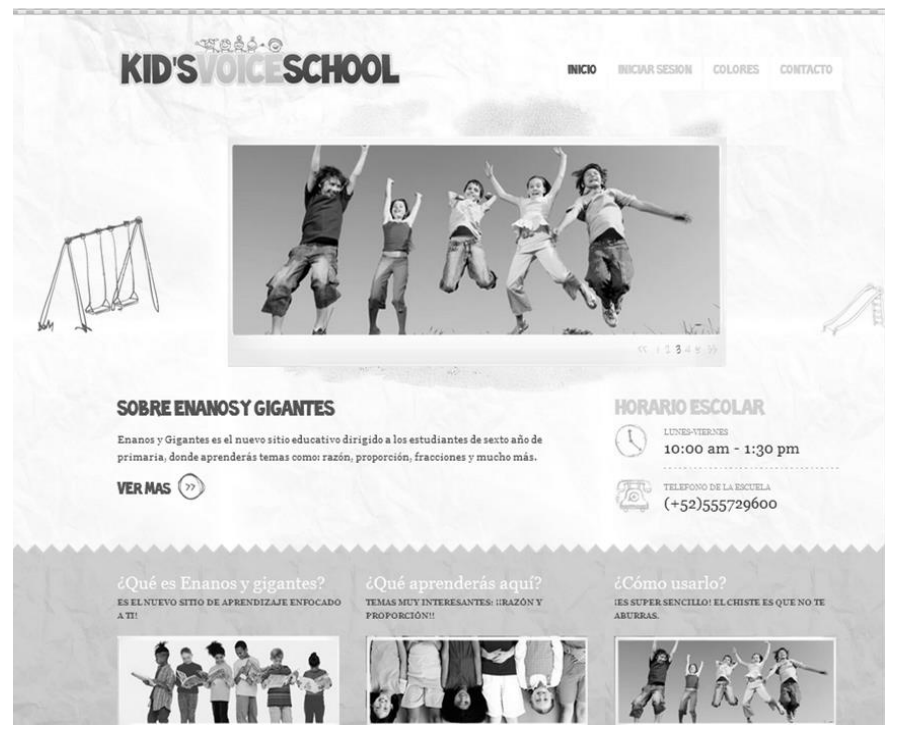

Fig. 2. Main screen (screenshot in Spanish).

The following figures show the screen for the teacher.

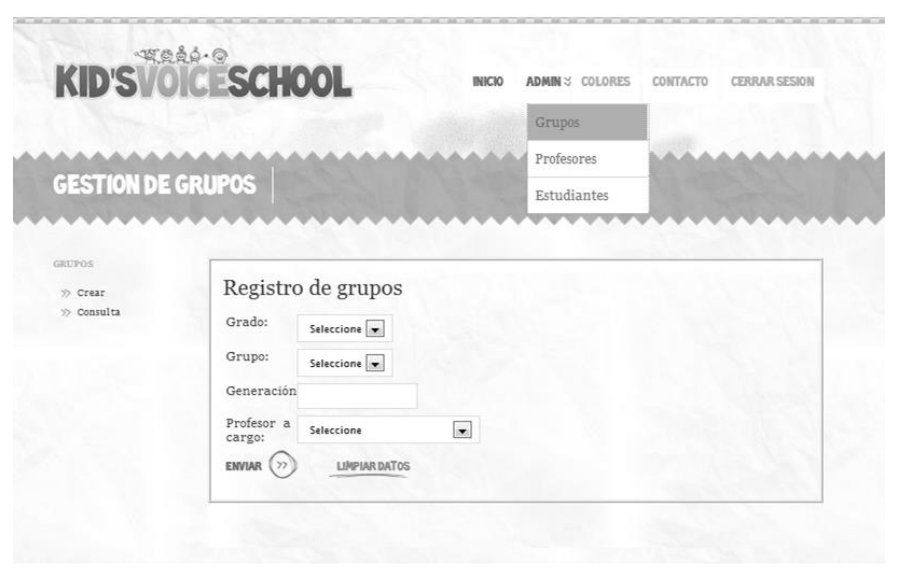

Fig. 3 Teacher's interface (screenshot in Spanish).

\section{$5 \quad$ Preliminary Results}

In collaboration with the elementary school "Jaime Torres Bodet", working with the A and the B sixth grade groups, 58 students. There was technological and pedagogic validation of Dwarfs and Giants. Technologically speaking some aspects were verified: information distribution, content of the visual interface, colors, size and typography according to the students 'opinion, this is done by asking for the colors, shapes and use of computer they prefer. 
On the pedagogic side, students use Dwarfs and Giants first to answer the diagnostic questionnaire and then the activities of proportional thinking and finally they answer an evaluation to compare the initial and final knowledge after using this tool.

According to the technological verification, the results are the following ones:

- $\quad 90 \%$ of our sample think that the distribution of graphic interface is a proper one to their age, which means they get familiar with the images shown and they are well distributed with no too much information.

- $52 \%$ point out the typography is the right one which is the Comics Sans MS, having a 14 and 16-pixel letter size, Dwarfs and Giants uses a similar source with sizes 12 and 24 pixels which adapts to the students "preference

- The students' favorite colors are: Violet, Red, Green, Turquoise and blue, all of them but violet are considered in Dwarfs and Giants when choosing from the list of colors to personalize the interface.

Qualitative analysis: Schooling teaching has not made good use of the students' qualitative thinking around proportionality, this was observed when focusing on the average correct answers which were in one of the dimensions of the figures they were asked to either reduce or maximize. Visualizing a complete drawing without focusing on its single parts so that we can choose the reduction of the original one that suggests that we need to work more on the qualitative aspect of the proportionality, so it was considered as an aspect that must be done by using the VLE Packages and big.

In some cases, for some students the qualitative aspect is poorly set out as the previous step of the quantitative aspect since the linguistic categories detected in them are the following ones: "it is bigger than...", "it is smaller than..." which reflects certain rudimentary understanding of the proportion, there were no other categories through which they would show a better understanding of the idea about proportion.

There was confusion for them when establishing relation between lengths so it was necessary to emphasize it to get the notion of ratio through the VLE. The familiarity that both students have with the drawing done to scale was recognized when part of the drawing was already done, that is why the predominance over law of closing prevailing in them was pointed out.

The difficulty detected is not recognizing the scaling factor $\left(x^{3}\right)$ in this kind of task. It was observed that children can easily fill out a table by adding certain times the same number or by multiplying, once the corresponding scaling operator is found. The problem detected employing the table was that the students did not extract the data from it when responding to the situation caused.

There was no comment by the students taking into account the different ways of representation: that of the table, that of the drawing, and the numerical one; when solving the classified problems "as the ones having a lose value", question tasks are in this category, thought the situations were different, but one which was solved by most students in the group.

Some other aspect considered to be a students' frequent answer was using the strategy of the unit value when solving some homework which matches what some researchers have found including the theoretical framework of this document, interested in recognizing strategies while solving ratio and proportion problems. After having 
worked on Dwarfs and Giants, students answered final questions and they got a significant improvement talking about the concepts ratio and proportion.

Almost totally, students expressed a development of their proportional thinking either qualitatively or quantitatively speaking. Most of them recognize reduction and widening as a specific way of proportion. They used mathematical concepts as they are understood, as ratio and proportion, recognizing the first one as relations between lengths and the second one as a relation of equivalence between reasons

Many ways of representing were employed: that of the drawing, on the table, and the numerical one, which was observed when doing some tasks of the final questions.

Despite what has been pointed out, there are topics that were slightly set out therefore it is necessary to do some more research on them, as the case of employing two symbolic systems of representation, the use of reverses, relying on the operators to establish ratios.

Statistical Analysis: The percentage of correct answers obtained by the group on the initial questionnaire was $47.2 \%$ and after employing the Virtual Environment of Learning, Dwarfs and Giants, the percentage of the correct answers on the final questionnaire was $73.2 \%$. Considering a paired-sets the results before and after the use of the application as a paired-sets and that different subject had specific initial knowledge of the topic, then the mean was computed for each condition. Then, the difference from each student was obtained and finally the average of differences was tested in order to check if it was significantly different. The results of the t-student showed a meaningful difference $(\mathrm{p}<0.005)$.

\section{Conclusions}

It has been seen that the use of technology in the teaching-learning process has had great advantages in recent years, but it is not only important to use technology but also three important aspects must be taken into account while developing educational software: what and how to teach and the tools (methodology, standards, technologies) the developing ones.

The first aspect is crucial, knowing why we choose such topic, as for us and as mentioned there are deficiencies in mathematics in the elementary schools in Mexico, in the case of the topics of ratio and proportion which are attached to the proportional thinking, these are the bases of mathematical branches which are Algebra, Trigonometry, calculus, etc. and other sciences: Physics, Chemistry, etc.

The second step once the topic or course has been defined, we must look for pedagogic fundamentals that use educational techniques to lecture the topic, Dwarfs and Giants is based on the teaching models developed by Ruiz [10], they got good results proven in black and white.

In the final step, it is important to define the process of development software which best adapts to the client's needs, besides using the adequate tools to guarantee success of such development.

Using standards in educational software has great advantages which are reusability, portability, scalability of activities and courses; portability due to having an established model, lets us integrate easily some more content in either the courses or the activities. Something else is taking into account the target population, in this case Dwarfs and 
Giants has got a young population, 8 to 10 years old children, so this makes developers take the visual issue as something really important, design and distribution of the page tin order to get children's interest, so as not to bore them and resulting in a lower performance, pedagogically speaking.

\section{References}

1. Mendoza, S.: El docente y el uso de las TICs del aula de medios en la escuela secundaria. Available at: http://biblioteca.ajusco.upn.mx/pdf/27685.pdf (2011)

2. INEGI: Panorama sociodemográfico de México. Available at: http://www3.inegi. org.mx/sistemas/Panorama2015/2015.Web/Contenido.aspx\#EstadosUnidosMexica $\operatorname{nos} 33000$ (2015)

3. Gobierno de la República.: Plan Nacional de Desarrollo 2013-2018. México, DF. Available at: http://pnd.gob.mx (2013)

4. OCDE: Programa para la Evaluación Internacional de los Alumnos (PISA). PISA 2012 Resultados. Available at: http:// www.oecd.org/centrodemexico/medios/ Mexico\%20Country\%20Note_SPANISH_final\%20GR1_EGcomments_02_12_201 $3 \% 20$ final.pdf (2012)

5. UIT: Medición de la sociedad de la información. Available at: https://www.itu.int/ en/ITU-D/Statistics/Documents/publications/mis2013/MIS2013-exec-sum_S.pdf (2013)

6. Ruiz, E. F.: Estudio de estrategias de solución y una propuesta de Enseñanza de razón y proporción. Tesis para obtener el grado de Doctor en Matemática Educativa, Cinvestav-IPN, México (2002)

7. Piaget, J., Inhelder, B.: Psicología del niño. Decimoséptima edición, Editorial Morata, Madrid (2007)

8. Diez, H.: Gestión del conocimiento para entornos de enseñanza - aprendizaje con enfoque constructivista basado en el método científico. Tesis para obtener el grado de Doctor en Ciencias en la especialidad de ingeniería Eléctrica, Cinvestav-IPN, México (2002)

9. Miranda, G.: De los ambientes virtuales de aprendizaje a las comunidades de aprendizaje en línea. Revista Digital Universitaria, Vol. 5, No. 10, pp. 1-14 (2004)

10. Sharable Content Object Reference Model. SCORM, Available at: http://www.scorm.com

11. IEEE: Standard for Learning Object Metadata Std 1484.12.1-2002. IEEE Standard for Information Technology - Education and Training Systems - Learning Objects and Metadata, Institute of Electrical and Electronical Engineers (2002)

12. HIRADHAR: Preet Pankaj. Integrating e-learning into English language enhancement: designing quality content for effective learning (2016)

13. SEP: Programa Sectorial de Educación 2013-2018. Available at: http://www.sep. gob.mx/es/sep1/programa_sectorial_de_educacion_13_18\#.VLAS1CuG9qU (2013)

14. Carmona, K., Olivares, M.: Las TIC en educación: metaanálisis sobre investigación y líneas emergentes en México. Apertura, Vol. 8, No. 2, pp. 100-115 (2016)

15. Acosta, E., Gordillo, A.: Technology-enhanced assessment process: issues affecting e-assessment uptake. ECORFAN Journal-Mexico, pp. 6-15 (2015)

16. SIP-IPN: Desarrollo de Recursos Educativos Digitales y Paradigma de Ambiente de Aprendizaje Apoyado en TIC para los Cendi del IPN. Reporte de Proyecto multidisciplinario SIP 20150296, Sistema SAPPI-IPN (2016)

17. Isiaka, R. M.: An Enhanced Learning Technology System Architecture for WebBased Instructional Design. International Journal of Emerging Technologies in Learning, Vol. 11, No. 1 (2016) 
Elena Fabiola Ruiz Ledesma, Lorena Chavarría Báez, Laura Ivonne Garay

18. Martín, M.: Aplicaciones de las bases de datos cliente servidor. Tesis Doctoral, Benemérita Universidad Autónoma de Puebla, Facultad de Ciencias de la computación (2004)

19. Tycho Press: Scrum Basics: A Very Quick Guide to Agile Project Management. First edition, Tycho Press, United States (2015) 